\title{
O FASCISMO NO CONDOR? O DEBATE SOBRE A IDEOLOGIA FASCISTA NAS DITADURAS MILITARES DO CONE SUL
}

\author{
Guilherme da Conceição de Lima ${ }^{1}$
}

\begin{abstract}
RESUMO: O artigo aborda como certos aspectos do fascismo podem ser encontradas como características do plano Condor (autoritarismo, censura, criação de um inimigo, perseguição política),através de observações sobre a discussão historiográfica sobre a temática, além de retrataras práticas coercitivas destes governos totalitários contidas nos testemunhos e documentos acerca da Operação Condor. O presente trabalho parte, portanto, para uma discussão teórica e apontamentos levantados por pesquisadores do tema em que certa medida podemos perceber elementos contidos nos regimes fascistas tradicionais presentes dentro das ditaduras militares do Cone-Sul na segunda metade dó século XX. Desta maneira, o artigo discute como os regimes militares pertencentes ao plano Condor continham caracteres fascistas dentro de sua estrutura institucional, influenciando as ações destes Estados.
\end{abstract}

Palavras-chave: Fascismo; Plano Condor; Ditaduras; Repressão.

\section{FASCISM IN THE CONDOR? THE DEBATE ON ELEMENTS OF FASCIST IDEOLOGY IN MILITARY DICTATORSHIP IN THE SOUTH CONE.}

ABSTRACT: The article discusses how certain aspects of fascism can be found as characteristics of the Condor plan (authoritarianism, censorship, creation of an enemy, political persecution), through observations on the historiographical discussion on the theme, as well as portraying the coercive practices of these totalitarian governments. contained in the testimonies and documents about the Operation Condor.The present work, therefore, starts with a theoretical discussion and notes raised by researchers on the subject to which extent we can perceive elements contained in the traditional fascist regimes present within the military dictatorships of the Southern Cone in the second half of the 20th century. In this way, the article discusses how the military regimes belonging to the Condor plan contained fascist characters within their institutional structure, influencing the actions of these states.

Keywords: Fascism; Condor Plan; Dictatorships; Repression.

\section{SOBRE O FASCISMO}

Para abordarmos a relação entre a ideologia fascista e as ditaduras do cone sul envolvidas na Operação Condor, é preciso antes de tudo situar os principais aspectos

\footnotetext{
${ }^{1}$ Bacharel e licenciado no curso de História pela Universidade Federal De Santa Catarina(UFSC). Atualmente mestrando da pós-graduação em história da Universidade Federal da Integração LatinoAmericana (UNILA). E-mail: guilherme.2lima@gmail.com

Programas de Pós-Graduação em Ciências Sociais e Filosofia - UNIOESTE - Rua da Faculdade 645. Toledo - PR. CEP 85.903-000 Email: revistaalamedas@gmail.com
} 
referentes a o que é o fascismo em si. É importante ressaltar os predicados inseridos dentro da concepção do ideário fascista afim de evitarmos os anacronismos. É de vital relevância deixar isto claro, pois os modelos nazifascistas dos estados europeus do entreguerras do século XX (Espanha, Itália e Alemanha), contém estruturas e conjecturas em vários aspectos diversos daquelas contidas pelos regimes ditatoriais abarcadas pela operação Condor.

O plano Condor foi um pacto entre as ditaduras militares da América do Sul (Brasil, Argentina, Bolívia, Chile, Paraguai, Uruguai). Firmado em 1975 entre os militares destes países secretamente, a operação Condor tinha o intuito de estreitar as relações de cooperação internacional das ditaduras em seus métodos de repressão e perseguição a opositores políticos destes regimes. Este acordo foi feito em 26 de novembro de 1975 no Chile, e o nome Condor fazia alusão a ave símbolo nacional do Chile, o condor andino. Estes governos foram organizados e criados através de golpes militares pondo o controle dos países na mão das forças armadas. A instauração destes regimes contou com apoio dos setores mais conservadores da sociedade, se utilizando do clima de instabilidade política destas nações para pôr em pratica projetos de poder e modelos econômicos encampados pelos apoiadores dos golpes, sejam a classe hegemônica nacional ou de potências estrangeiras, neste caso os Estados Unidos, em que a guerra fria fazia os estadunidenses apertarem ainda mais o laço de dominação em sua esfera de influência na América Latina (SOUZA, 2011).

Mas porque falar de fascismo especificamente nestes regimes, sendo que pela teoria política de estado eles não se encaixariam nos moldes tradicionais do fascismo? A resposta é que o fascismo não é somente uma nomenclatura ou um modelo de governo originado durante o período entre guerras mundiais no século XX. O Fascismo não é somente uma nomenclatura ou um modelo de governo originado durante o período entre as guerras mundiais no século XX. Boa parte das características do fascismo enquanto pensamento político de tomada de ações por instituições e indivíduos pode ser observado em outras formas de governo, até mesmo em democracias, lembrando que o partido nazista participou de eleições democráticas na república de Weimar, antes de chegar ao poder. Robert Owen Paxton (2007) explana que a gênese do fascismo está presente na sociedade, e não é algo exclusivo de uma região ou país, já que acaba se manifestando geralmente em momentos de instabilidade da sociedade agindo pelo 
medo, receio e ódio instigado pelo senso comum, buscando culpados e bodes expiatórios para atitudes violentas e antidemocráticas. Perseguição a minorias e adversários políticos fazem parte deste esquema, como as ações da Alemanha nazista contra a população de origem judaica e os membros dos partidos de oposição, sobretudo o partido comunista. Como Paxton expõe, o fascismo é uma força de "[...] um amálgama poderoso dos ingredientes distintos, mas combináveis, do conservadorismo, do nacional socialismo e da direita radical, unidos por inimigos em comum e pela mesma paixão pela regeneração, energização e purificação da nação [...]" (PAXTON, 2007, p. 336). O fascismo enquanto ideia política assume as mais variadas facetas dentro de uma sociedade. Sua condição e nascedouro estão implicados em uma determinada conjuntura política, social e econômica que possibilita sua ascensão, principalmente ligada a crises, sejam elas institucionais, econômicas e sociais.

Como observado por Nicos Poulantzas (1978), a análise do fascismo revela que seus traços possibilitam uma melhor compreensão da própria natureza do estado capitalista e das problemáticas que um estudo aprofundado acaba por derivar, sobretudo em como atuam a pequena burguesia e a classe média no seio do fascismo. Indo por esta perspectiva, a relação entre ideologia e as relações políticas é essencial para compreender o fascismo, se valendo da concepção de que a ideologia é uma soma de ideias, pensamentos e ações que agregam para a reprodução e manutenção da sociedade como um todo (CHAUI, 1984). A pequena burguesia e a classe média foram a principal força social que o fascismo angariou em prol de sua causa. O fascismo acaba se aproveitando da ideologia pequeno burguesa. Historicamente a pequena burguesia tende a se inclinar aos setores mais conservadores e das classes hegemônicas, tendo uma relação de afastamento e até mesmo de oposição as camadas mais baixas da sociedade. Portanto a pequena burguesia acabou tomando para si o projeto fascista, que faria com que ela retomasse a ordem e estabilidade social atacada pelas diversas crises econômicas e sociais que estavam gerando greves e instabilidade financeira. Mesmo com certa crítica ao grande capital e discurso um tanto quanto anticapitalista presente (angariando apoio até em setores da classe trabalhadora), a principal adesão das massas ao fascismo tanto na Alemanha de Hitler quanto na Itália de Mussolini veio da classe média e pequena burguesia. A defesa incondicional e o fanatismo do movimento foram abraçados entusiasticamente por ambas, sendo o alicerce e base social de suas tomadas 
de ação.

É Nesta Perspectiva que a obra de Wilhelm Reich, "Psicologia de Massas do fascismo, pode contribuir para o debate acerca de elementos fascistas presentes não só nas ditaduras militares pertencentes a operação Condor, mas sim até mesmo se manifestar em ambientes concebidos politicamente como democráticos, inclusive na atualidade. Fascismo nada mais é que a expressão estrutural do caráter do homem médio, na medida em que suas vontades e desejos acabam sendo reprimidos pelos costumes e cultura da sociedade a qual pertence. $\mathrm{O}$ fascismo é posto por Reich como ação emocional e irracional do ser humano oprimido.

Oliveira e Cruz (2009) dissertam de que o fascismo possui um caráter e influência mecanicista quando se manifesta, denotando o fascismo como um movimento de psicologia de massas enquanto fenômeno que se aproveita da irracionalidade humana, definido desta forma por Reich:

O fascismo é um fenômeno internacional que permeia todos os corpos da sociedade humana de todas as nações. [...]. As minhas experiências em análise do caráter convenceram-me de que não existe um único indivíduo que não seja portador, na sua estrutura, de elementos do pensamento e de sentimentos fascistas. [...]como o fascismo é sempre e em toda a parte um movimento; apoiado nas massas, revela todas as características e contradições da estrutura do caráter das massas humanas: não é, como geralmente se crê, um movimento exclusivamente reacionário, mas sim um amálgama de sentimento de revolta e ideias sociais reacionárias. [...] O fascismo, na sua forma mais pura, é o somatório de todas as reações irracionais do caráter do homem médio. (REICH, 2001, p. 12)

\section{O DEBATE SOBRE O FASCISMO NA OPERAÇÃO CONDOR}

Contudo, a discussão de estabelecer as ditaduras do Plano Condor como fascistas adentra em um campo de intenso debate, pois vai na direção das narrativas bem como na construção memorial destes governos ditatoriais, de como eles estão enquadrados historicamente.João Fábio Bertonha (2015, p. 205) ressalta que devemos ter um cuidado com o termo "fascista" ao adota-lo para as ditaduras sul-americanas, para evitar anacronismos e confusões entre os regimes fascistas clássicos, e aqueles comandados pelos militares na América do Sul.

Hélgio Trindade (2000) denota que neste debate para se compreender as origens e métodos aplicados pelos regimes militares, pesquisadores como Jorge Tápia Valdés, 
Joseph Comblin, Agustin Cueva, Zavaleta Mercado e Theotonio dos Santos, amparados pelas ideias marxistas, acabaram por utilizar o termo "fascismo" para classificá-los sociologicamente. Eles seriam a versão mais atual do modelo fascista, em que os militares e as forças armadas atuariam como partidos de massa. Ricardo Souza Mendes (2013) discorre por exemplo, em como Joseph Comblin e Jorge Tapia Valdés abordam o fascismo dentro da constituição ideológica dos regimes militares latino-americanos.

Comblin (1979) ressalta que a Doutrina de Segurança Nacional (DSN) elaborou um Estado forte, centralizador e peça-chave na determinação de uma ordem social, numa conjunção de proposições precisas e bem articuladas. Comblin assim põem isto como uma configuração de uma ideologia pertencente a estes regimes totalitários, e usa de duas premissas régias para esta finalidade: a geopolítica e a guerra total. De acordo com a geopolítica no plano externo, a América Latina por estar situada no Ocidente, deveria obrigatoriamente se aliar as ideias e perspectivas do mundo ocidental, no caso os EUA e seus aliados europeus. Internamente, estes países deveriam estabelecer uma identificação única entre estado e nação. Já a guerra total entraria num contexto da bipolaridade entre Ocidente e Oriente, comunismo contra capitalismo. Os pregadores da DSN seguiam a premissa de que a luta contra o comunismo na verdade, era uma questão de sobrevivência. A DSN seguiria então com a prerrogativa de estabelecer "objetivos nacionais", que seriam constituídos de métodos combativos de contrarrevolução, que tinham como meta identificar, eliminar e exterminar por completo membros ou simpatizantes de quaisquer doutrinas socialistas e comunistas, pondo fim a qualquer oposição a estes regimes. Isto aliado a uma elaboração de um ambiente dentro da sociedade civil que buscaria extrair qualquer elemento de espectro comunista. (MENDES, 2013 p. 14-15).

Sendo mais visceral que Comblin, Jorge Tápia Valdés parte da ideia de um fascismo dependente. Valdés frisa as ações e conduta das elites civis de direita com inclinações fascistas para a propagação do ideário da DSN. Ele ressalta que a Doutrina de Segurança Nacional era um modelo especifico que estabelecia uma certa forma de se pensar a política, a economia e a sociedade. O regime seria legitimo amparado por características vitais para alcançar seus fins: autoridade pela política, censura e violência. Outro ponto levado em conta por Valdés é o conhecimento da relação nos regimes fascistas de estado e direito. $\mathrm{O}$ nazi-fascismo parte da dicotomia binária entre 
amigo-inimigo, elaborando um sujeito outro completamente oposto, que deve ser extirpado. Desta forma, seria o Estado encarregado de eliminar esta suposta ameaça. Isto também foi incorporado pelas ditaduras seguidoras da DSN, em que a perseguição e aniquilação do inimigo era prática rotineira. Com isso, todo o sistema jurídico seria fragmentado, sendo imposta uma hierarquização de normas e valores, abarcando em seu bojo também a esfera jurídica. Por esta mirada, o fascismo latino-americano fora configurado não com o endosso das "massas" amparadas em um partido político, mas feito de cima para baixo, através do aparelhamento do estado sob o domínio da burguesia assegurado pela força militar. Como Mendes (2013) detalha sobre as ideias de Valdés, o fascismo latino-americano também incluiria o terror, onde ele [...]"tornava-se o principal instrumento de obtenção dos objetivos políticos, ferramenta básica para a subordinação da sociedade adotando a detenção arbitrária, o desaparecimento, o assassinato e os campos de concentração. "[...] (MENDES, 2013, p. 22).

Fazendo o contraponto as ideias de Valdés e Comblin, temos Alain Rouquié e sua obra $O$ Estado Militar na América Latina. Publicado originalmente em 1982, o livro retrata a militarização dos processos políticos na América Latina. Roquié, como ressalta Mendes (2013 p. 33), vai relativizar os impactos da DSN na América-Latina. Ao contrário das perspectivas de Comblin e Valdés, para ele os regimes militares não possuíam uma ideologia especifica. Na verdade, a DSN seria uma ferramenta que visava velar o quanto estes governos seriam ilegítimos, do que assegurar a legitimidade dos mesmos. As ideias contidas na Doutrina de Segurança Nacional não formariam um cerne ideológico nem seriam um substituto para o mesmo, sequer teria essa funcionalidade. De acordo com Roquié, para se compreender as ditaduras latinoamericanas da segunda metade do século XX, não se pode fiar-se somente no modelo adotado pela DSN, mas sim em como foram montadas estruturalmente e a base de formação das forças armadas Latino-Americanas. As características do militarismo latino-americano derivam em: controle interno do estado cada vez mais nas mãos dos militares; um isolamento acarretado pela tecnização ligado ao processo de modernização; e por fim, a inexistência na prática dentro das forças armadas, de conflitos internos e de cunho político, que facilitou a compreensão do papel de estabilizador dos militares. (MENDES, 2013, p. 33).

Outro autor que também contesta esta conceituação de que as ditaduras do Cone 
Sul seriam do ponto de vista político fascistas, é o brasileiro Francisco C.T. Silva (2000). Silva vai denotar que a DSN, sendo entendida como ferramenta ideológica utilizada pelos Estados Unidos Da América para assegurar a região da América do Sul como sua zona de influência, faria com que as ditaduras do Cone Sul estivessem submetidas aos interesses financeiros internacionais. Logo é incongruente, dentro das características da ideologia fascista, atrelar estes interesses estrangeiros com os da pátria-nação. Indo além, um dos cernes do fascismo é uma ojeriza concreta ao liberalismo econômico, pois para os fascistas um dos grandes causadores dos males que pode assolar sua nação seria este liberalismo. No caso das ditaduras pertencentes ao plano Condor, é exatamente o oposto: todas elas tiveram intensos processos de privatizações e abertura do capital nacional para o mercado internacional (FERNANDES, MORETT, 2018, p.43-44). O caso mais evidente é o do Chile, que foi laboratório para as teses neoliberais da escola de Chicago capitaneadas pelas teses econômicas de Milton Friedman, o que aprofundou ainda mais a dependência econômica chilena aos interesses financeiros exteriores. (CALDÉS, 1995).

Também se tem a perspectiva da Teoria política. Como bem apontado por João Fábio Bertonha (2015, p. 206-207), partindo de uma análise dentro do campo da ciência política, os governos pertencentes à operação Condor não se encaixam nos moldes tradicionais do fascismo, pois alguns elementos dos regimes fascistas tradicionais não se encontram nestas ditaduras, sobretudo na ideia de um Estado organicamente hierarquizado, amparado em uma figura de liderança incontestável partindo de um partido político único, que difundiria uma ideologia una, incorporando toda a sociedade em torno de si. Este partido único serviria como o grande promotor do regime. Ele estabeleceria uma relação total, pois “[...] iria além de uma simples negação de outros ou de uma estrutura amorfa para acomodar interesses, mas uma real máquina de mobilização popular e transmissão ideológica [...]" (BERTONHA, 2015, p. 207).

- Porém isto não invalida a presença de aspectos fascistizantes, tampouco a influência destas ideias dentro das instituições e de certos setores da sociedade dos países pertencentes ao Plano Condor. Tomemos como indicativo a ditadura chilena de Augusto Pinochet. A classe média chilena foi uma das principais apoiadoras do golpe de 1973, devido ao temor deste setor da sociedade com as greves e a os movimentos operários chilenos, endossando a nova ordem política que surgiu com a ditadura militar, 
esta evidentemente repressiva. Para estes, a ditadura chilena acabou por "derrotar o mal", encarnada na figura do presidente deposto Salvador Allende e a classe operária chilena, que visava transformar o Chile em uma "segunda Cuba" latino-americana. Seguindo os ditames da ideologia de segurança nacional, foi preciso eliminar os "inimigos internos" da ordem dentro do Chile, a qualquer custo. Rafaella de Aguiar Coradini (2017) destaca que os militares chilenos e seus colaboradores optaram pela via do golpe, levando este a cabo da instauração do terrorismo e perseguição política estatal, se valendo de métodos de tortura e eliminação física de seus opositores. Este apoio político que boa parte dos setores de classe média chileno deram, explica muito de um silenciamento paulatino da sociedade frente as arbitrariedades cometidas pelo governo de Augusto Pinochet.

Também é preciso ressaltar a influência e auxílio que a extrema-direita fascista prestou ao ideário dos militares mais antigos destes Estados, que vivenciaram os regimes fascistas europeus das décadas de 20 e 30 do século XX, tendo um importante papel para o surgimento das ditaduras sul americanas, constituindo uma bela ferramenta para entender o surgimento destes regimes e suas especificidades. (BERTONHA, 2013, p. 209). Isto se deve sobretudo que muitos destes militares antigos participaram durante as décadas de 30 e 40 de movimentos similares ao fascismo em seus países, como a Legião Cívica Argentina, criada em 1931 pelo general José Félix Uriburu. (BEIRED, 2000, p. 307). No Brasiltivemos a presença de ex-membros da Ação Integralista Brasileira (AIB) como agentes do Golpe civil-militar em 1964. A Ação Integralista Brasileira foi o maior partido fascista surgido fora da Europa, durante os anos 1930. (BERTONHA, 2013).

Agustin Cueva (2013) detalha que a caracterização dos regimes de exceção do Cone Sul em fascistas ou não está muito distante em constituir uma fórmula mágica que seja eficaz em desvendar com precisão total a linha política exata dos governos militares da região no período da aplicação da Doutrina de Segurança Nacional e do Plano Condor. Mesmo a caracterização concreta dos governos militares da América do Sul como fascistas ou sua negativa, não encerram as pesquisas e investigações sobre a influência do pensamento fascista neste período. Estudos mais aprofundados acerca deste tema podem representar uma conceituação e melhor elaboração em como a historiografia, bem como a ciência política, podem perceber as nuances de caracteres 
fascistas para além do recorte histórico do entreguerras do século XX, e como este tipo de ideologia pode se espraiar na história do nosso tempo presente e em seu contexto de pluralismo político.

\section{PARA ALÉM DO FASCISMO: REPRESSÃO, TORTURA E TERRORISMO DE ESTADO NA OPERAÇÃO CONDOR}

A discussão de afirmar ou não de que as ditaduras pertencentes a Operação Condor em fascistas ou não, acaba por derivar na complexidade de determinismo conceituais e de certa forma, no uso pejorativo destes. Pode-se passar a impressão de que estas ditaduras seriam muito mais nefastas e escabrosas se fossem consideradas fascistas, o que é um erro. Um regime ditatorial totalitário e repressivo por si só não necessita de adjetivos negativos para tornar-se o que já é: um governo que oprime e sujeita sua população as mais terríveis privações.

O que se realmente deve se destacar neste contexto, foram os métodos de repressão e do terrorismo de estado aplicado pelos agentes responsáveis pela operação Condor. O Plano Condor se tornou uma organização transnacional de trocas de informação, experiências, treinamentos e auxílio mútuo dos órgãos de repressão, tortura e perseguição aos seus opositores. Amparado pela Doutrina de Segurança Nacional e o Terrorismo de Estado, as ditaduras do Cone Sul vão basear todos os seus projetos e ações repressivas contra os elementos considerados "indesejáveis" à ordem estabelecida, o combate ao subversivo. Segundo Mariana Joffily:

É na base da prioridade dada à questão da segurança nacional que se estabelece como fator mobilizador o confronto do "inimigo interno", ou seja, um ser indeterminado, de perfil político elástico, que pode ser qualquer um. Argumento central utilizado por regimes que impediam o funcionamento de leis e normas de proteção aos cidadãos, para sequestrar, prender, torturar e até executar aquelas pessoas "qualificadas" como "inimigas internas", ou seja, subversivas e/ou potenciais subversivos contra a ordem vigente(JOFFILY, 2018, p. 5).

Com isso a operação Condor se organizava através da instituição de uma política de medo e terror que se espraiava pelos países pertencentes ao pacto entre as ditaduras.

Aqueles enquadrados nesta perspectiva de agentes da "subversão" eram 
perseguidos e torturados, como demonstrado pelo relato de Claudio Niro, mantido clandestinamente como prisioneiro da ditadura militar argentina (1976-1983):

\begin{abstract}
Outro grupo da guarda eram os nazis. Quando vinham, o faziam ovacionando a Hitler, cantando uma canção que diz: "Aí vem Adolfo pela rua, matando judeus para fazer sabão". Estes verdugos punham gravações onde se escutava a voz de Hitler e quando vinham buscar-nos nos golpeavam com toda a fúria, produzindo a ruptura dos ossos de alguns dos detidos. O problema de estar encapuzado é de não saber de onde procedem golpes e, portanto, permanecer em um estado de total indefesa. Estes tipos se entusiasmavam obrigando-nos a fazer ginástica militar (corpo ao solo, saltos de rã, etc.), mantendo-nos algemados na parede, durante horas. Gritavam contra nós, no meio dos ruídos das cadeias e ameaçavam-nos com a picana se não cumpríssemos com a consigna. Efetivamente, se alguém não resistisse, com este tratamento, era levado a casa 2 onde se encontrava o quirófano. Ali se torturava pelo simples prazer de torturar. Com um total sadismo. Enquanto tudo isto se passava, escutávamos na televisão o Mundial de 78. Cada vez que um rival fazia um gol na Argentina era muito triste para nós, porque os verdugos descontavam moendo-nos a pau. (NIRO, ZARANKIN, 2008, p 187-188).
\end{abstract}

A descrição relata o divertimento que o grupo de guardas e torturadores sentia em obrigar os seus prisioneiros a situações e condições vexaminosas, imergindo-os em atos repletos de violência tanto física quanto psicológicapelo simples prazer de torturar, como mesmo afirma Niro em seu testemunho. Como abordado por Bauer (2008, p. 19), também se tem o comportamento do torturador e dos indivíduos responsáveis pelas práticas de tortura e caça aos inimigos dos regimes. O sadismo nas torturas e os métodos utilizados para fazer as vítimas falarem e denunciarem companheiros eram tremendamente desumanos. Muitos se eximiam da culpa por acreditarem piamente que estavam recebendo ordens hierarquicamente superiores baseada no código militar. Contudo, diversos registros e testemunhos presentes em comissões da verdade e investigações pós ditaduras, revelam os cruéis métodos utilizados pelos torturadores a mando dos órgãos de repressão, como o conhecido Nunca Más da Argentina. Caroline Silveira Bauer (2008) escreve que o Nunca Más foi organizado pela Comisión Nacional sobre la Desaparición de Personas (CONADEP), criada em 1983 pelo governo de Raúl Alfonsin após o fim da ditadura militar argentina. O CONADEP foi importante, pois se tornou o precursor de diversas outras comissões com semelhante temática pelos países do Cone Sul, como a Comissão da Verdade brasileira e a Comisión Verdad y Reconciliación chilena. Publicado em 1984, o Nunca Más trazia depoimentos e detalhes de como funcionavam os meandros dos crimes cometidos contra os direitos humanos 
pela ditadura argentina. O informe do Nunca Más desnuda de forma clara, com provas cabais e documentos oficiais, como órgãos do Estado elaboraram um complexo aparato de repressão, se utilizando de sequestros, tortura, morte, desaparecimentos e outras ilegalidades.

\section{CONSIDERAÇÕES FINAIS}

Com certeza estabelecer as ditaduras do plano Condor como fascistas, sob a ótica da ciência política e em comparação aos regimes nazifascistas das décadas de 30 e 40, podem nos levar a labirintos de questionamentos e respostas dúbias e imprecisas. Contudo, é possível delinear que muitos aspectos fascistas estavam presentes na macroestrutura estatal representada pelos órgãos governamentais e os agentes responsáveis pela repressão e Terrorismo de Estado. Percebendo como os indivíduos atuavam na conjuntura, influenciado por um ambiental que o encorajava a portar uma determinada postura, é que se possibilita uma compreensão geral de como certas estruturas do fascismo estavam presentes dentro da Operação Condor. Dito isto, é preciso ressaltar que o fascismo é uma ideologia que não necessariamente está presa somente a uma época. Ele consegue fazer-se presente na atualidade, basta ver a o apoio e aumento de atitudes e discursos de ódio de governantes com pensamentos de extremadireita e fascistas, como no caso dos chefes de Estado de países como Hungria e Polônia, tendo posturas de negar os crimes cometidos pelo nazismo na segunda guerra. Ainda na Europa temos o crescimento dentro da Alemanha do AFD (Alternativa para a Alemanha, em alemão: Alternative für Deutschland), partido claramente influenciado pela doutrina nazista, e na França Marine Le Pen, representante da nova extrema-direita francesa, é uma força política a se considerar atualmente. Manifestações de neonazistas crescem ao redor do globo, o caso mais evidente ocorreu em Charlotesville nos Estados Unidos da América em 2017, onde ocorreu um protesto realizado por grupos neonazistas e de extrema-direita contra a remoção de um monumento do general Confederado Robert E. Lee, em que estes entraram num confronto com grupos antifascistas. Se junta a isso a escalada do terrorismo doméstico (ataques terroristas cometidos por cidadãos do próprio país, geralmente pertencendo ao grupo étnico dominante da população) estadunidense desde a eleição de Donald Trump em 2016, 
vitimando sobretudo imigrantes e minorias étnicas, alvos preferidos dos discursos de ódio nos EUA. No Brasil, após a deposição da presidenta Dilma Rousseff, ressurgiu com força os discursos voltados para a criminalização da esquerda, amparadas em uma paranóia de um suposto anticomunismo presente no imaginário político conservador brasileiro, o que influenciou na eleição presidencial de 2018 que teve como resultado a eleição de Jair Messias Bolsonaro, político famoso por sustentar um discurso racista e preconceituoso contra negros e LGBT's, além de contar com apoio de grupos de extrema-direita, cristãos conservadores e militares. Este panorama montado gerou um aumento de crimes de ódio no Brasil e ataques sistemáticos ao trabalho de imprensa (FENAJ, 2020). Como se pode perceber, o fascismo é um pensamento que transcende períodos ou recortes históricos específicos.

Para se compreender esse nosso presente, é necessário então voltarmos aos desenrolares de nosso passado, a fim de entender como chegamos ao estágio atual de sociedade, daí a importância de pesquisas e investigações sobre o Plano Condor. Leonardo Marmontel (2014, p. 133) evidencia a importância de estudos referentes à Operação Condor e seus efeitos e desenrolares. A disputa pela revelação dos acontecimentos e a condenação daqueles que praticaram atos criminosos durante este período permanece difícil e insuficiente. Já vão mais de 45 anos em que foi firmado o pacto da Operação Condor, e as informações referentes à totalidade e o tamanho de seu alcance não estão bem desveladas, permanecem indefinidas no seu montante. Muitas evidências e documentos acabaram se perdendo ou foram eliminados intencionalmente, de modo que muitos crimes acabem permanecendo impunes por não terem mais nenhuma evidência documental física, perdidas pelo esquecimento e das práticas de destruição da memória, como a queima e ocultação de fontes e documentos de interesse público. Novos fatos, pesquisas, estudos vão revelando as peças do enorme quebra cabeça deste momento histórico, com o objetivo de desnudar os crimes cometidos neste período e as facetas dos criminosos que os cometeram.

Ao analisar os documentos e transcrições dos relatos indeléveis das torturas e operações realizadas pelos responsáveis da Operação Condor, o trato com a memória e o respeito devem ser totais. As particularidades das situações envolvidas, bem como a relação intrínseca entre os mais variados aspectos políticos, sociais, culturais, econômicos e psicológicos devem ser levados em conta. Documentos serão apenas 
dados reunidos se não tivermos as chaves de interpretação para deles extrair informações e transformá-los em fontes históricas concretas. A história não é o retorno total ao passado, “[...] mas a memória pode lhe fornecer o fio de Ariadne, o vínculo carnal do qual ela, ainda assim, tem necessidade para tornar o passado inteligível. Ela o faz escutar outras vozes que iluminam os fragmentos de realidades passadas. "[...] (JOUTARD, 2007, p. 234).

\section{REFERÊNCIAS BIBLIOGRÁFICAS}

BAUER, Caroline Silveira. A produção dos relatórios Nunca Mais na Argentina e no Brasil: aspectos das transições políticas e da constituição da memória sobre a repressão.Revista de História Comparada (UFRJ), v. 3, 2008. 19 p.

Um estudo comparativo das práticas de desaparecimento nas ditaduras civil-militares argentina e brasileira e a elaboração de políticas de memória em ambos os países. $445 \mathrm{f}$. Tese (Doutorado em História) - Universidade Federal do Rio Grande. 2007.

BEIRED, José Luis Bendicho. A grande Argentina: os nacionalistas e o sonho de potência latino-americana.Revista Brasileira de História, vol. 21, nº 42, p. 303-322, 2001.

BERTONHA, João Fábio. Sobre fascismos e ditaduras: a herança fascista na formatação dos regimes militares do Brasil, Argentina e Chile. Revista de História Comparada (UFRJ), v. 9, p. 203-231, 2015.

BRAGA, Leonardo Marmontel. A internacionalização do terror: o caso argentino. 225 f. Dissertação (Mestrado em Relações Internacionais) - Universidade Federal do Rio Grande do Sul, Porto Alegre. 2013.

CALDÉS, Juan Gabriel. Pinochet's Economists - The Chicago School in Chile.Cambridge, Cambridge University Press, 1995, 334 páginas.

CHAUI, Marilena. O que é Idelogia. São Paulo, Brasiliense, 1984.

COGGIOLA, Osvaldo. Governos militares na América Latina. São Paulo: Contexto, 2001.

COMBLIN, Joseph. Ideología de segurança nacional. Rio de Janeiro: Paz e Terra, 1979.

CORADINI, Rafaella Aguiar. Y Los Clandestinos, Dónde Están? Rastros da Ditadura Chilena, de 1973 a 1990. 2017. Dissertação (Mestrado em História) Universidade Federal de Santa Maria. 
CUEVA, Agustín. Autoritarismo y fascismo en América Latina. Centro de Pensamiento Crítico. Biblioteca Agustín Cueva. Serie: Cuadernos Políticos No. 2. Equador, Quito 2013.

DINGES, John. Os anos do Condor: Uma década de terrorismo internacional no Cone Sul. São Paulo, Cia das Letras, 2005.

ECO, Umberto. O Fascismo Eterno. Rio de Janeiro: Editora Record, 2002. FENAJ. Violência contra jornalistas e liberdade de imprensa no Brasil. Relatório 2019. Federação nacional dos jornalistas - FENAJ. Brasília, 2020.

FERNANDES, Hiago Rangel; MORETTI, Matheus Teixeira. As Ditaduras Militares da América Latina e o fenômeno do fascismo: uma análise comparativa. Revista Multidisciplinar Discente Mundo Livre, p. 29-47. 2018.

FINCHELSTEIN, Federico. La Argentina fascista, Los orígenes ideológicos de la dictadura.Buenos Aires: Editorial Sudamericana, 2008.

FUCKS, Mario Pablo. Reich e a relação entre psicanálise e política. Instituto Sedes Sapientia, São Paulo, 2018. p. 17

FUNARI, Pedro. Paulo. ZARANKIN, Andrés; REIS, José A. Arqueologia da Repressão e da Resistência: América Latina na era das ditaduras (1960-1980). São Paulo: Annablume; Fapesp, 2008.

HERRERA, Genaro A. El pensamiento político de los militares. Santiago: Centro de Investigaciones Socioeconómicas, 1986. $6^{\text {a }}$. Edição

JOFFILY, Mariana. Terrorismo de Estado na Argentina e a violência sexual: algumas reflexões sobre esta prática e seus desdobramentos durante o período democrático. XIV Encontro Estadual de História - ANPUH RS - Democracia, Liberdades, Utopias. 2018. 17 P. p 5.

JOUTARD, Philippe. Reconciliar história e memória. Escritos: revista da Casa de Rui Barbosa, Rio de Janeiro: Edições Casa de Rui Barbosa, ano 1, n. 1, p. 223-235, 2007. p. 234

MARIANO, Nilson. As garras do condor: como as ditaduras militares da Argentina, do Chile, do Uruguai do Brasil, da Bolívia e do Paraguai se associaram para eliminar adversários políticos. Petrópolis/RJ: Vozes, 2003.

MARMONTEL, Leonardo. "Operação Condor: A internacionalização do terror".Estudios Avanzados 21 (Santiago, jun. 2014) p. 111- 136 
MENDES, Ricardo Antonio Souza. Ditaduras civil-militares no Cone Sul e a Doutrina de Segurança Nacional - algumas considerações sobre a Historiografia. Revista Tempo e Argumento, Florianópolis, v. 5, n.10, jul./dez. 2013. p. 06 - 38.

MIX, Miguel Rojas. El dios de Pinochet: Fisonomía del fascismo Iberoamericano. Buenos Aires, Prometeo Libros, 2007.

OLIVEIRA, Dayse Maria; CRUZ, Maria Helena Simão. Sobre a Psicologia de Massas do Fascismo de W. Reich. Revista psicologia e saúde, v. 1, p. 70-76, 2009.

OLIVEIRA, Luciano. Ditadura militar, tortura e história: a "vitória simbólica" dos vencidos. Revista Brasileira de Ciências Sociais (Impresso), v. 26, p. 7-25, 2011.

PADRÓS, Enrique Serra. Ditaduras de Segurança Nacional em regiões de fronteira: o Rio Grande do Sul e a rede de Direitos Humanos. In: XVII Simpósio Nacional de História - Conhecimento Histórico e Diálogo Social, 2013, Natal. Conhecimento Histórico e Diálogo Social, 2013. 16 p.

PAXTON, R. O. 2007. A anatomia do fascismo. São Paulo, Paz e Terra, 420 p.

REICH, Wilhelm. Psicologia de Massas do Fascismo. Tradução: Maria da Graça M. Macedo. $3^{\text {a }}$. ed. São Paulo: Martins Fontes. 2001

ROUQUIÉ, Alain. O Estado Militar na América Latina. Rio de Janeiro: , AlfaÔmega, 1984.

SILVA, Francisco C. T. "Os Fascismos".In: REIS, Daniel A. (org). O século XX: o tempo das crises. Rio de Janeiro: Civilização Brasileira, 2000. p. 111-162

SOUZA, Farias Fabiano. Operação Condor: Terrorismo de Estado no Cone Sul das Américas. Aedos: Revista do Corpo Discente do Programa de Pós-Graduação em História da UFRGS, v. 3, p. 159-176, 2011.

TRINDADE, Helgio. O fascismo e o neo-fascismo na América Latina. In: Luiz Milman; Paulo Vizentini. (Org.).Neo-nazismo, negacionismo e extremismo político. 1ed.Porto Alegre: Editora da Universidade/UFRGS, 2000, v., p. 51-78.

.El tema del fascismo en America Latina. Revista de estudios politicos, v. 10, n.30, p. 131-147, 1982.

VALDÉS, Jorge Alberto Tapia. El terrorismo de Estado: la doctrina de la seguridad nacional en el Cono Sur. México (DF): Editorial Nueva Imagen, 1980 